\title{
Microstructure and Mechanical Properties of Wire + Arc Additively Manufactured 2050 Al-Li Alloy Wall Deposits
}

Hao Zhong ${ }^{1,2}$, Bojin Qi ${ }^{1,2}$, Baoqiang Cong ${ }^{1,2^{*}}$, Zewu Qi ${ }^{1,2}$ and Hongye Sun ${ }^{1,2}$

\begin{abstract}
Aluminum-Lithium (Al-Li) alloy is a topic of great interest owing to its high strength and light weight, but there are only a few applications of Al-Li alloy in wire + arc additive manufacturing (WAAM) process. To identify its feasibility in WAAM process, a special AA2050 Al-Li alloy wire was produced and employed in the production of straight-walled components, using a WAAM system based on variable polarity gas tungsten arc welding (VP-GTAW) process. The influence of post-deposited heat treatment on the microstructure and property of the deposit was investigated using optical micrographs (OM), scanning electron microscopy (SEM), X-ray diffraction (XRD), hardness and tensile properties tests. Results revealed that the microstructures of AA2050 aluminum deposits varied with their location layers. The upper layers consisted of fine equiaxed grains, while the bottom layer exhibited a coarse columnar structure. Mechanical properties witnessed a significant improvement after post-deposited heat treatment, with the average micro-hardness reaching $141 \mathrm{HV}$ and the ultimate tensile strength exceeding $400 \mathrm{MPa}$. Fracture morphology exhibited a typical ductile fracture.
\end{abstract}

Keywords: Aluminum-copper-lithium alloy, Wire arc additive manufacturing, Heat treatment, Mechanical properties

\section{Introduction}

Nowadays, the requirement for lightweight alloy in the aerospace and highspeed train industries is increasing. Aluminum alloys containing lithium feature low density and high specific strength, making them one of the most competitive lightweight alloys. The strength of Aluminum-Lithium alloy is comparable to 2024 aluminum alloy, while the density of Al-Li alloy is much lower [1]. Since components manufactured using $\mathrm{Al}-\mathrm{Li}$ alloy can be $10 \%-15 \%$ lighter in weight and $15 \%-20 \%$ higher in rigidity, $\mathrm{Al}-\mathrm{Li}$ alloy has become an ideal structural material in the aerospace and aviation industries [2]. However, a major concern is the manufacture of complex parts, which is common in aircraft, without loss.

Additive manufacturing (AM) that produces components layer-by-layer according to a digital model, is a

\footnotetext{
*Correspondence: congbq@buaa.edu.cn

${ }^{1}$ School of Mechanical Engineering and Automation, Beihang University, Beijing 100191, China

Full list of author information is available at the end of the article
}

new paradigm for designing and building intricate parts widely used in the aerospace industry [3]. As a category of AM, Wire + arc additive manufacturing (WAAM) utilizes an electric arc as the heat source and wire as the raw material [4-7]. WAAM enables an increase in the design freedom, deposition rate, and density of deposits [8]. Furthermore, due to the application of the GMAW/GTAW system, equipment cost is substantially reduced [9] and large-scale metallic structures can be directly deposited [10]. WAAM therefore has attracted enormous attention in the aerospace industry, especially for the production of structural parts of airplanes using $\mathrm{Al}$ alloy [11].

The property of wire is crucial to the deposit quality as the wire provides raw material for deposition. The influence of wire on the final product has attracted great interest from researchers. Cong et al. [12-14] adopted ER2319 $\mathrm{Al}-\mathrm{Cu}$ wire to the WAAM process using cold metal transfer (CMT) and GTAW, finding that the porous surface of the wire, which was susceptible to absorbing $\mathrm{H}_{2} \mathrm{O}$ and other impurities, causes porosity. Bo et al. [15] also adopted ER2319 to WAAM, finding that welding current, welding 
speed and inter-layer temperature influenced weld width. Bai et al. [16] built a thin wall with ER4043 Al-Si wire using TIG-WAAM and analyzed the microstructure and property of the deposit. It was determined that the content of Si element in wire had an influence on the formation of $\mathrm{Al}-\mathrm{Si}$ eutectic. Gu et al. [17] further studied how the quality of ER4043 wire affected the quality of WAAM parst, finding that wire quality had a profound influence on the final products in respect of surface, microstructure, porosity and mechanical properties. In Ref. [18], attention was paid to manufacturing the 4043 WAAM components using CMT to increase the deposition rate as well as to obtain favorable formability. Wang et al. [19] characterized the advantages and disadvantages of processing parameters in CMT deposition of ER4043. They concluded that adjusting parameters could control the energy input process as well as metal transfer behavior to design and optimize the weld properties for each special CMT application. Geng et al. [20] investigated geometric limitation and tensile properties of WAAM 5A06 Al-Mg alloy parts, where anisotropy tensile properties can be seen between the directions parallel and perpendicular to texture orientation. Ying et al. [21] applied 5356 to the WAAM process and investigated the relation between inter-layer cooling time and forming quality of WAAM parts. Huang et al. [22] applied 5A06 to the WAAM process using the GTAW system and studied how preheating temperature influenced morphologies of deposits. As described in the above literature, a wide range of aluminum alloys, including $\mathrm{Al}-\mathrm{Cu}, \mathrm{Al}-\mathrm{Si}$, and $\mathrm{Al}-\mathrm{Mg}$ series, have been used in WAAM processes to employ the advantageous properties of different alloys. It is important to study the feasibility of different wires in the WAAM process before applying it to industry.

There have been a few attempts to conduct the WAAM process with $\mathrm{Al}-\mathrm{Li}$ alloy, and there is no commercial Al$\mathrm{Li}$ alloy wire designed for the WAAM process. This paper therefore aims to apply a special AA2050 Al-Li wire to the WAAM process in the production of straight-walled components. The formation feature, microstructure and properties of the deposits are discussed in this paper, in addition to the impact of post-deposited heat treatment. The obtained results are believed to be valuable for the development of novel $\mathrm{Al}-\mathrm{Li}$ alloy wires dedicated only to the WAAM process.

\section{Experimental Procedures}

Experiments are carried out on a WAAM system, as seen in Figure 1a. The system contains a self-developed variable polarity gas tungsten arc welding (VP-GTAW) power supply, a moving working table, wire feeder system, and TIG torch. Pure argon is selected as the shielding gas. The waveform of the VP-GTAW power supply is shown in Figure 1b. A $12 \mathrm{~mm}$ thick $2 \mathrm{~A} 12$ plate is chosen
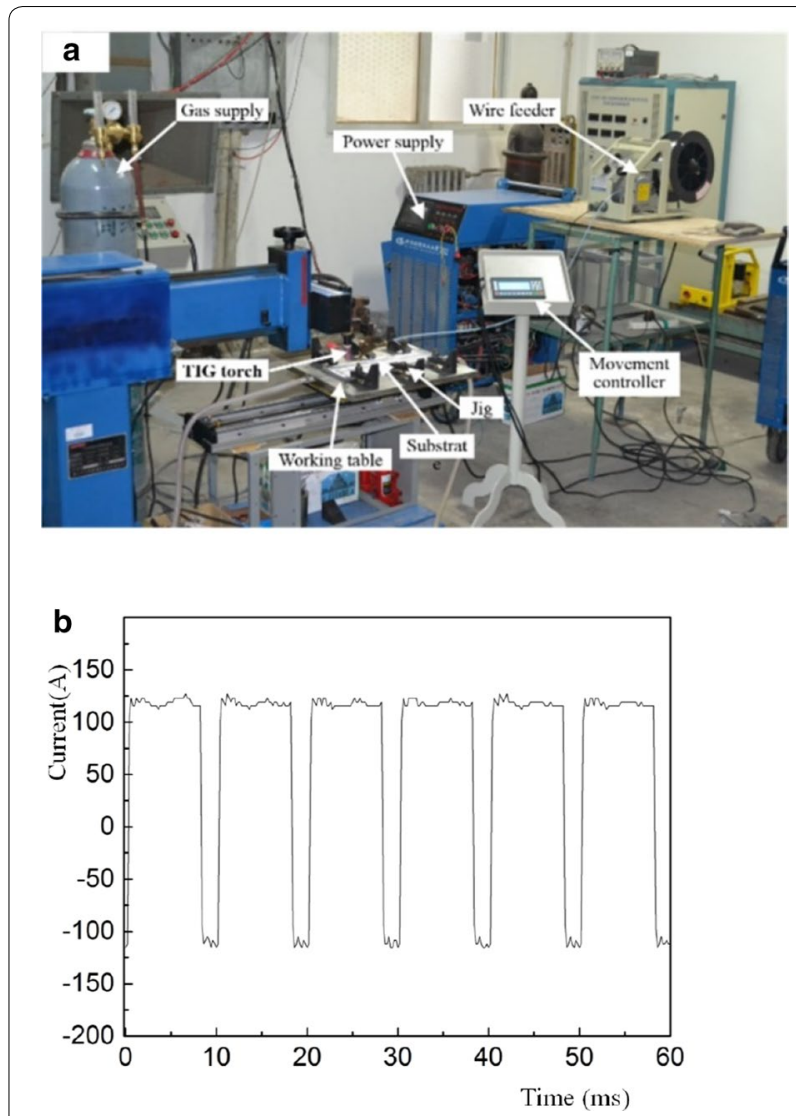

Figure 1 a WAAM experimental system and $\mathbf{b}$ current waveform for depositing AA2050 straight wall sample

as the substrate. Before the experiment, the substrate was wiped with acetone prior to mechanical polishing to eliminate oxide film. AA2050 wire developed by the University of South California, USA is used as the feedstock. The main chemical composition of the wire is $3.55 \% \mathrm{Cu}$, $1.0 \% \mathrm{Li}, 0.40 \% \mathrm{Mg}, 0.45 \% \mathrm{Ag}$ and $\mathrm{Al}$ as the balance. SEM and EDS results suggest that $\mathrm{Cu}$ is the main alloy element and is distributed in the $\mathrm{Al}$ matrix as particle chemical compounds and solutes, as shown in Figure $2 \mathrm{~b}$.

A straight thin wall was built layer by layer. A variable pulse of 100 A positive current and 120 A negative current with a duration time ratio of 4:1 was adopted in this experiment. Wire feeding speed and travel speed were $1.8 \mathrm{~m} / \mathrm{min}$ and $300 \mathrm{~mm} / \mathrm{min}$, respectively. The distance between substrate and welding torch was $12 \mathrm{~mm}$, and the diameter of the tungsten electrode was $3.2 \mathrm{~mm}$. The flow rate of argon was $15 \mathrm{~L} / \mathrm{min}$ during the deposition. The length of the built wall is $170 \mathrm{~mm}$ by measurement. The average height and width of the layer are $1.25 \mathrm{~mm}$ and $6.55 \mathrm{~mm}$, respectively by calculation (the total height of the wall is $35 \mathrm{~mm}$, and there are 28 layers).

Deposits under two different conditions, as-deposited $(\mathrm{AD})$ and post-deposition heat-treated (PHT), were 

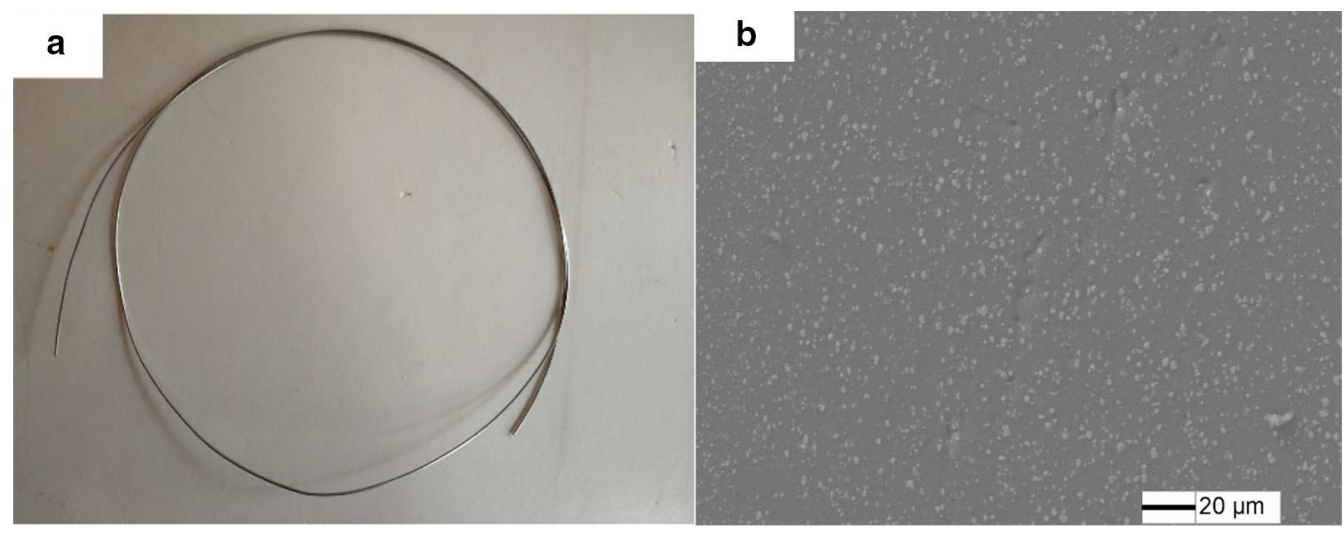

Figure $\mathbf{2}$ a Profile and $\mathbf{b}$ SEM of AA2050 wire

investigated. The post-deposition heat treatment (T6) contained solution treatment and artificial aging. The samples were heated to $530{ }^{\circ} \mathrm{C}$ at a ramping speed of $200{ }^{\circ} \mathrm{C} / \mathrm{h}$ from room temperature and kept at this temperature for $30 \mathrm{~min}$ in the furnace. A cold-water quench took place within $10 \mathrm{~s}$ after solution treatment. Subsequently, artificial aging treatment was carried out at $165^{\circ} \mathrm{C}$ for $24 \mathrm{~h}$. The ramping speed was $100^{\circ} \mathrm{C} / \mathrm{h}$.

The wall components were cut along the cross-section. The samples were mounted, ground, polished and etched with Kroll's reagent $\left(\mathrm{HNO}_{3} 6 \mathrm{~mL}\right.$; $\mathrm{HF} 2 \mathrm{~mL} ; \mathrm{H}_{2} \mathrm{O}$ $92 \mathrm{~mL}$ ). Microstructures were observed using optical microscopy (OM) (Leica DMi8). Phases were examined with X-ray diffractometer (D/Max-2200pc. Micro-area composition analysis was performed by means of energy dispersive spectrometry (EDS) detected with a scanning electron microscopy (SEM) (Camscan-3400). Vickers micro-hardness measurements were carried out using a Zwick/Roell ZHV30 Vickers indentation test machine to determine the micro-hardness of the specimen along the vertical direction perpendicular to the welding direction. A load of $200 \mathrm{~g}$ for $15 \mathrm{~s}$ was applied to make the indentations. Due to material limitations, a tensile test was carried out only in the post-deposited heat-treated sample with an electro-mechanical universal testing machine (SANS 5504) along the deposition direction. The loading rate was $1.5 \mathrm{~mm} / \mathrm{min}$ and the tensile test sample was machined as shown in Figure 3.

\section{Results and Discussions}

\subsection{Microstructure}

As shown in Figure 4, different types of grain structures can be seen in both AD and PHT samples according to their locations. The inter layers consist of coarse column grains as depicted in Figure 4a and c, while equiaxed grains dominate the inner layers of the

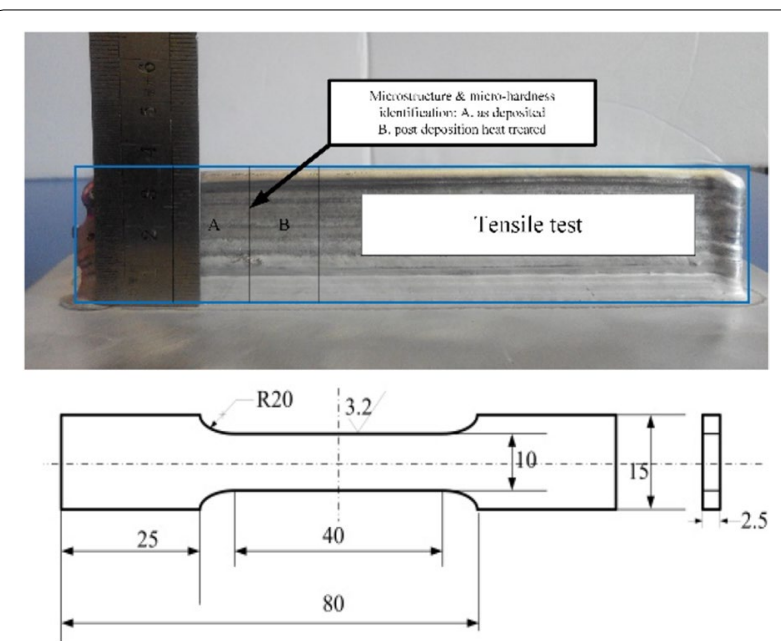

Figure 3 Schematic of WAAM AA 2050 component and tensile test specimen

deposits as shown in Figure $4 \mathrm{~b}$ and d. The distinct layered microstructure is formed because of the thermal gradient and cooling rate in and around the molten pool [23]. In general, temperature gradients play a dominant role in the direction of the grain growth, as the grain grows in the direction of the largest temperature gradient during solidification [24]. In the first few layers of deposition, heat dissipates faster as a consequence of lower heat accumulation and a shorter path of heat dissipation into the substrate [25]. The largest temperature gradient therefore appears to be perpendicular to the substrate, which is prone to columnar grain formation. With increasing height, the heat accumulates and dissipation slows down, resulting in a thermal balance. Consequently, the grains grow along each direction simultaneously, and finally the 

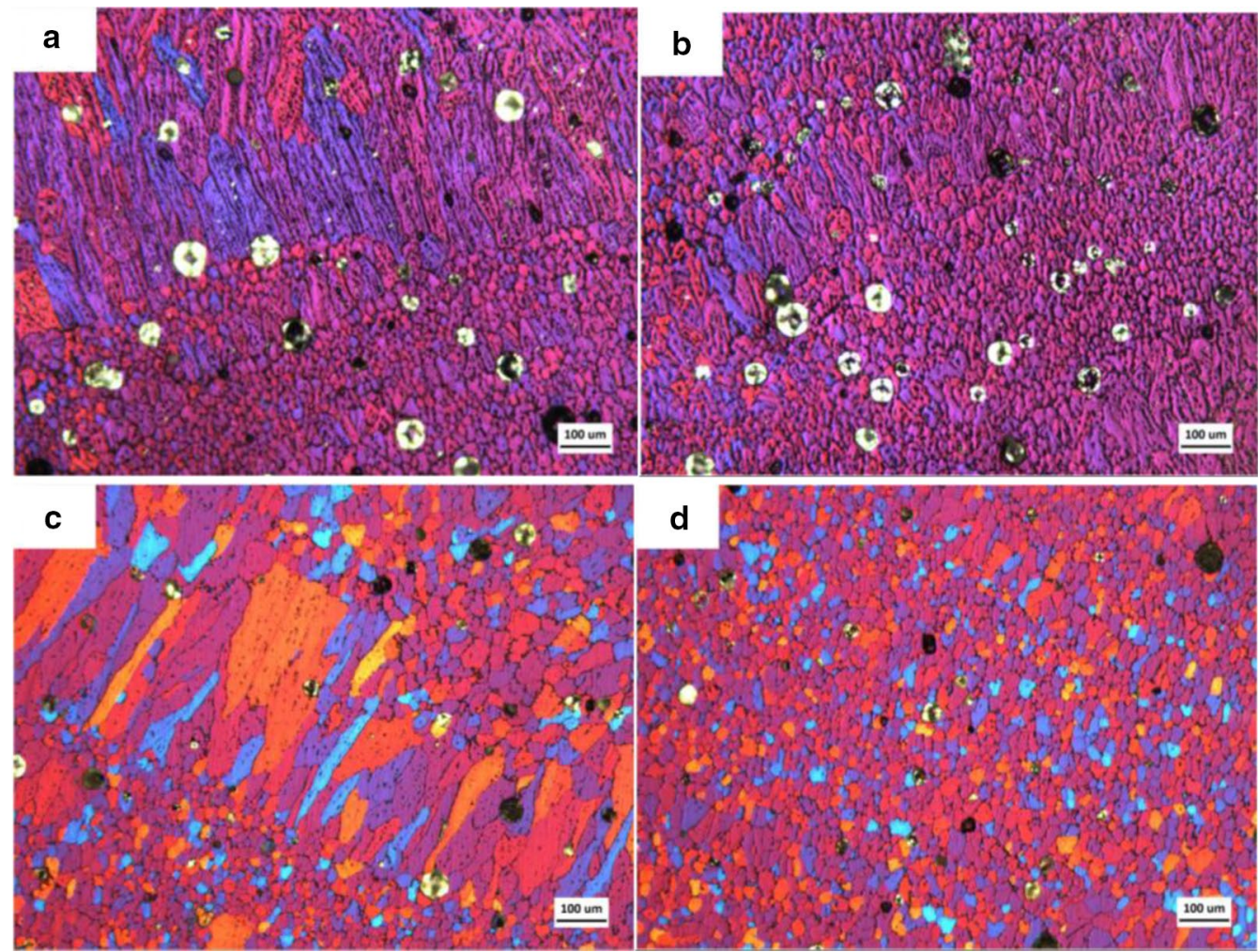

Figure 4 Grain structure of different areas of as-deposited $(\mathbf{a}, \mathbf{b})$ and PHT (c, d) deposits: $\mathbf{a}, \mathbf{c}$ inter layer; $\mathbf{b}$, $\mathbf{d}$ inner layer

equiaxed non-dendrite grains form during the inner layer area. In contrast to the inner layer region, the inter layer area is heated and melts repeatedly, leading to a coarser microstructure.

SEM and EDS results of the samples are presented in Figure 5. As revealed in the pictures, in the as-deposited sample, the white second phase particles, where $\mathrm{Cu}$ is the main alloy element, mainly distributed along the grain boundaries. Only a few of them are scattered in the grain. In the heat-treated sample, the second phase particles are the same as those in the as-deposited sample except that they are more dispersed. EDS area scan results are consistent with the analysis above in that the majority of $\mathrm{Cu}$ is distributed in the secondary phase, with a little $\mathrm{Cu}$ in the $\mathrm{Al}$ matrix. The XRD result presented in Figure 6 shows that the matrix phase is $\alpha-\mathrm{Al}$, and the secondary phase is $\theta\left(\mathrm{Al}_{2} \mathrm{Cu}\right)$ phase. A few $\delta^{\prime}\left(\mathrm{Al}_{3} \mathrm{Li}\right)$ phase particles are observed. Combining the results together, it can be inferred that the deposit of element $\mathrm{Cu}$ mainly precipitates as $\theta$ $\left(\mathrm{Al}_{2} \mathrm{Cu}\right)$ phase or dissolves in the grain. The content of $\delta^{\prime}\left(\mathrm{Al}_{3} \mathrm{Li}\right)$ phase is low due to the low content of $\mathrm{Li}$ in the AA2050 wire as well as a high burning loss of Li during the welding process.

\subsection{Mechanical Property}

Micro-hardness results are shown in Figure 7. The average micro-hardness of the as-deposited and PHT samples are $71 \mathrm{HV}$ and $141 \mathrm{HV}$ respectively, while that of the wire is 91HV. Micro-hardness of the heat-treated sample shows an increase by $98.6 \%$ compared to that of the as-deposited sample and by $55.0 \%$ compared to that of the wire. This is the result of solution strengthening and precipitation hardening. More $\mathrm{Cu}$ atoms dissolve into the $\mathrm{Al}$ matrix after solution treatment, resulting in an increase in lattice distortion, which helps prevent dislocation motion and therefore is beneficial to increase micro-hardness. In addition, after PHT, the second phase particles are more dispersed and distributed along the grain boundaries and in the grain, contributing to microhardness increase. Tensile tests indicates that the yield strength of the heat-treated sample reaches $260 \mathrm{MPa}$ and the ultimate tensile strength is $400 \mathrm{MPa}$ while the elongation is $5.0 \%$. Comparison with $2050 \mathrm{Al}-\mathrm{Li}$ alloy casting [26] and $2195 \mathrm{Al}-\mathrm{Li}$ alloy welded joint (ER 2319 as feedstock) [27] shows that the UTS of the PHT sample is lower than the UTS of the casting while higher than that of the welded joint. This can be explained by the addition of $\mathrm{Mg}$ and $\mathrm{Ag}$ [28]. Studies suggest that the 

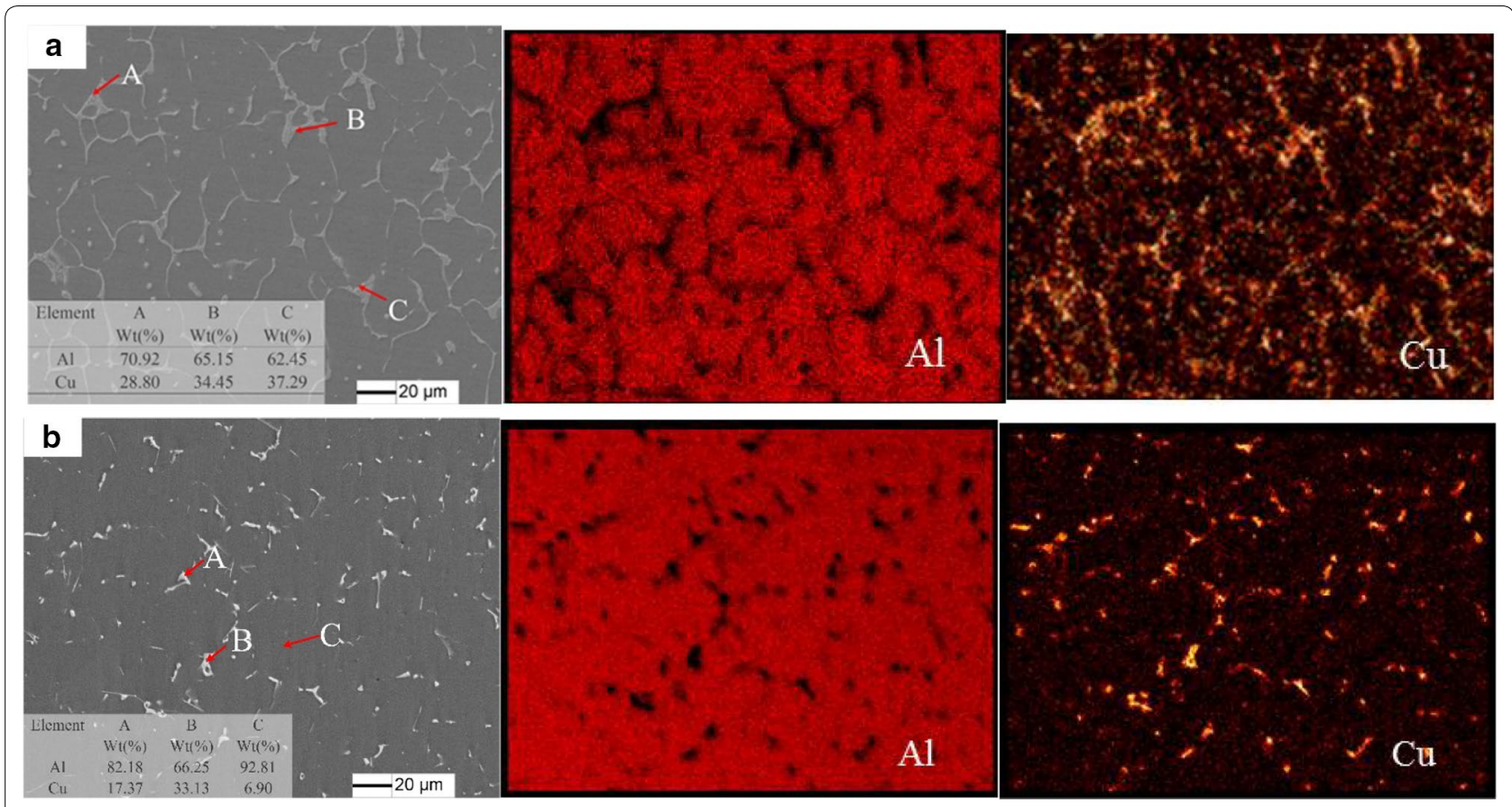

Figure 5 SEM and EDS results of AA 2050 WAAMed parts: $\mathbf{a}$ as-deposited, $\mathbf{b}$ heat-treated

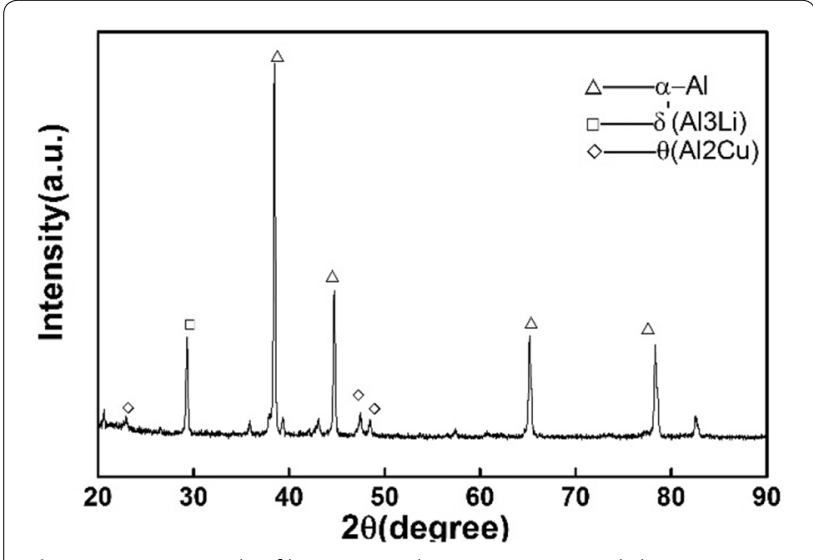

Figure 6 XRD result of heat treated AA2050 WAAMed deposit

presence of $\mathrm{Mg}$ and $\mathrm{Ag}$ can improve the aging strengthening effect of $\mathrm{Al}-\mathrm{Li}$ alloy by promoting the precipitation of $\mathrm{T} 1\left(\mathrm{Al}_{2} \mathrm{CuLi}\right)$ phase, which can enhance the mechanical properties of the deposit significantly [29]. Due to the burning loss of Li during the welding process in addition to the low content of $\mathrm{Li}$ in the raw material, the content of T1 phase is rather low, which is why the UTS of the sample is not comparable to that of casting.

Fracture morphology is presented in Figure 8. In the picture, several dimples and tearing ridges are

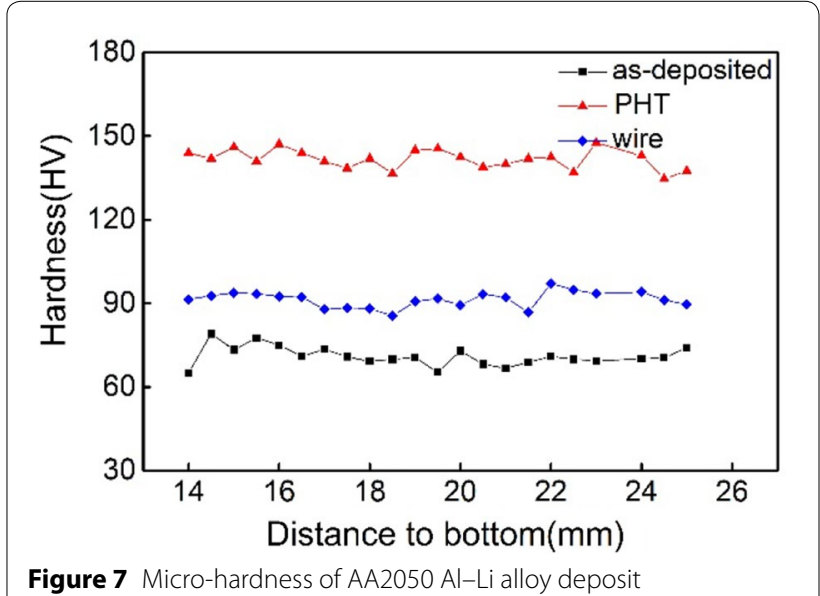

observed, which is typical of ductile fracture. Furthermore, there are secondary phase particles found in the center of some dimples, which can cause initiating primary cracks of fracture [11]. These small dimples grow and crack to form tearing ridges under static tensile pressure. The $\mathrm{Cu}$ solute atom depletion zones (SDZ) are typically formed around grain boundaries resulting from the dispersion distribution of the $\theta$ phase along the grain boundaries. These SDZ have an elevated risk of fracture under static tensile stress as they are weaker in strength compared to other areas. 


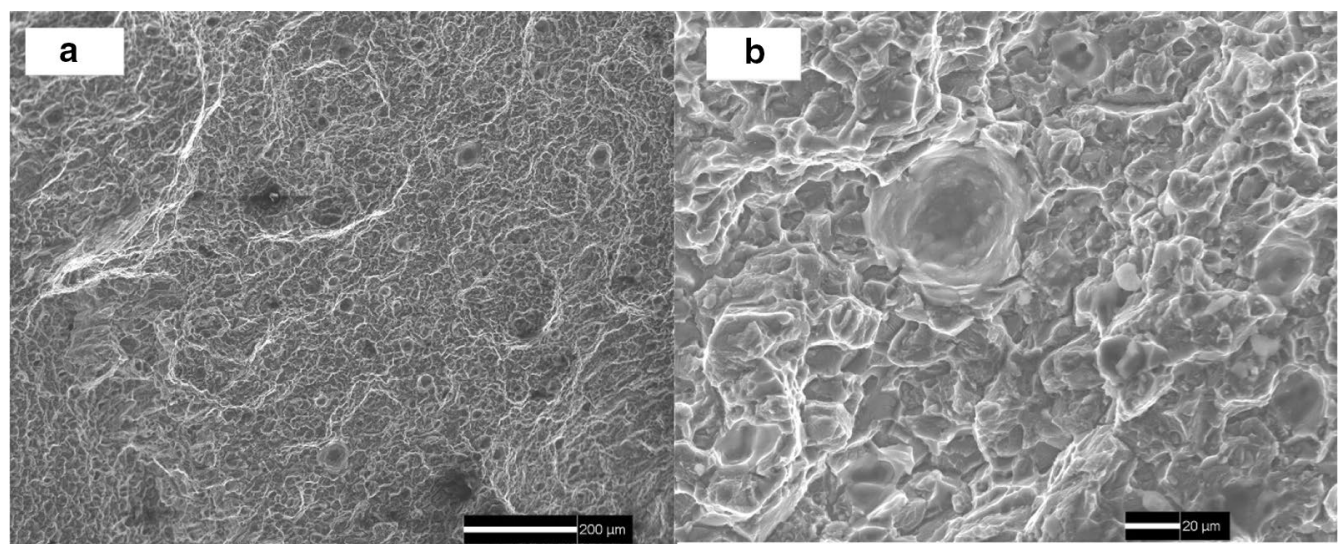

Figure 8 Fracture morphology of heat-treated AA2050 specimen under $\mathbf{a} \times 100 ; \mathbf{b} \times 500$ SEM

\section{Conclusions}

(1) A special AA2050 wire is used in the additive manufacturing of thin straight wall deposits. Excellent formability is achieved by adjusting the heat input using a VP-GTAW process.

(2) AA2050 Al-Li alloy WAAM components have a layered microstructure. The inner layers consist of fine equiaxed non-dendrite grains, comparing to the inter layers consisting of coarse columnar grains. The secondary phases, mainly $\theta\left(\mathrm{Al}_{2} \mathrm{Cu}\right)$ phase and $\delta^{\prime}\left(\mathrm{Al}_{3} \mathrm{Li}\right)$ phase, distribute dispersedly along the grain boundary after post deposited heat treatment.

(3) Post-deposited solution treatment and artificial aging (T6) can enhance the micro-hardness of the deposit significantly. The micro-hardness and UTS of the heat-treated deposit are $141 \mathrm{HV}$ and $400 \mathrm{MPa}$, respectively. The fracture morphology of heat-treated sample shows a typical ductile fracture characteristic.

\section{Authors' Contributions}

$\mathrm{HZ}$ analyzed the data and wrote this article. $\mathrm{BC}$ helped design the experiment and revised this article. $\mathrm{BQ}$ helped with problems refer to power source control. ZQ prepared the deposit analyzed in this article. All authors read and approved the final manuscript.

\section{Authors' Information}

Hao Zhong, born in 1994, is currently a doctoral candidate at School of Mechanical Engineering and Automation, Beihang University, China.

Bojin Qi is currently a professor at School of Mechanical Engineering and Automation, Beihang University, China.

Baogiang Cong is currently an associate professor at School of Mechanical Engineering and Automation, Beihang University, China.

\section{Acknowledgements}

The authors are grateful to be supported by the WAAMat Programme (http:// www.waammat.com). The authors are also willing to show gratitude to Xiao $\mathrm{LI}$ from the University of South California, USA, who is so kind to provide us with AA 2050 Al-Li wire designed for WAAM.

\section{Competing Interests}

The authors declare that they have no competing interests.

\section{Funding}

Supported by National Natural Science Foundation of China (Grant No. 51675031), Beijing Municipal Science and Technology Commission and Fundamental Research Funds for the Central Universities (Grant No. YWF-18-BJ-J244,YWF-19-BJ-J-232), Beijing Natural Science Foundation (Grant No. 3182020), and the Academic Excellence Foundation of BUAA for PhD.

\section{Author Details}

${ }^{1}$ School of Mechanical Engineering and Automation, Beihang University, Beijing 100191, China. ${ }^{2}$ MIIT Key Laboratory of Aeronautics Intelligent Manufacturing, Beijing 100191, China.

Received: 26 February 2019 Revised: 18 June 2019 Accepted: 23 October 2019

Published online: 21 November 2019

\section{References}

[1] H Chen, L Fu, P Liang, et al. Defect features, texture and mechanical properties of friction stir welded lap joints of 2A97 Al-Li alloy thin sheets. Materials Characterization, 2017, 125: 160-173.

[2] Y Yang, K Zhou, G J Li. Surface gradient microstructural characteristics and evolution mechanism of 2195 aluminum lithium alloy induced by laser shock peening. Optics \& Laser Technology, 2019, 109: 1-7.

[3] T Debroy, H L Wei, J Zuback, et al. Additive manufacturing of metallic components - process, structure and properties. Progress in Materials Science, 2018, 92: 112-224.

[4] ZW Qi, B Q Cong, B J Qi, et al. Microstructure and mechanical properties of double-wire + arc additively manufactured Al-Cu-Mg alloys. Journal of Materials Processing Technology, 2018, 255: 347-353.

[5] ZW Qi, B Q Cong, B J Qi, et al. Properties of wire + arc additively manufactured 2024 aluminum alloy with different solution treatment temperature. Materials Letters, 2018, 230: 275-278.

[6] ZW Qi, B J Qi, B Q Cong, et al. Microstructure and mechanical properties of wire plus arc additively manufactured Al-Mg-Si aluminum alloy. Materials Letters, 2018, 233: 348-350.

[7] ZW Qi, B J Qi, B Q Cong, et al. Microstructure and mechanical properties of wire plus arc additively manufactured 2024 aluminum alloy 
components: as-deposited and post heat-treated. Journal of Manufacturing Processes, 2019, 40: 27-36.

[8] SW Williams, F Martina, A C Addison, et al. Wire+arc additive manufacturing. Materials Science and Technology, 2015, 7(32): 641-647.

[9] JY Bo, J H Wang, J X Shi, et al. Microstructure and mechanical properties of 4043-Al alloy thin-walled components produced by additive manufacturing with TIG welding. Welding \& Joining, 2015, 10: 23-26. (in Chinese)

[10] H B Geng, J L Li, J T Xiong, et al. Geometric limitation and tensile properties of wire and arc additive manufacturing $5 \mathrm{a} 06$ aluminum alloy parts. Journal of Materials Engineering and Performance, 2017, 26(2): 621-629.

[11] J L Gu, J L Ding, S W Williams, et al. The strengthening effect of inter-layer cold working and post-deposition heat treatment on the additively manufactured al-6.3cu alloy. Materials Science and Engineering A, 2015, 651: 18-26.

[12] B Q Cong, R J Ouyang, B J Qi, et al. Influence of cold metal transfer process and its heat input on weld bead geometry and porosity of aluminum-copper alloy welds. Rare Metal Materials and Engineering, 2016, 45(3): 606-611.

[13] B Q Cong, HY Sun, P Peng, et al. Porosity control of wire + arc additively manufactured Al-6.3Cu alloy deposition using AC-GTAW process. Rare Metal Materials \& Engineering, 2017, 46(5): 1359-1364. (in Chinese)

[14] B Q Cong, Z W Qi, B J Qi, et al. A comparative study of additively manufactured thin wall and block structure with $\mathrm{Al}-6.3 \% \mathrm{Cu}$ alloy using cold metal transfer process. Applied Sciences, 2017, 7(3): 275-286.

[15] J Y Bai, J H Wang, S B Lin, et al. Width prediction of aluminium alloy weld additively manufactured by TIG arc. Transactions of the China Welding Institution, 2015, 36(9): 87-91. (in Chinese)

[16] J Y Bai, C L Yang, S B Lin, et al. Mechanical properties of 2219-Al components produced by additive manufacturing with TIG. The International Journal of Advanced Manufacturing Technology, 2016, 86(1-4): 479-485.

[17] J L Gu, J L Ding, B Q Cong, et al. The influence of wire properties on the quality and performance of wire + arc additive manufactured aluminium parts. Advanced Materials Research, 2014, 1081: 210-214.

[18] Y Liu, Q Sun, Y Jiang, et al. Rapid prototyping process based on cold metal transfer arc welding technology. Transactions of the China Welding Institution, 2014, 35(7): 1-4. (in Chinese)

[19] P Wang, S Hu, J Shen, et al. Characterization the contribution and limitation of the characteristic processing parameters in cold metal transfer deposition of an Al alloy. Journal of Materials Processing Technology, 2017, 245: 122-133.

[20] H Geng, J Li, J Xiong, et al. Optimization of wire feed for GTAW based additive manufacturing. Journal of Materials Processing Technology, 2017, 243: 40-47.

[21] Y H Yin, S S Hu, W L Liu, et al. Rapid prototyping of 5356 Al-alloy parts by argon tungsten-arc welding. Ordnance Material Science and Engineering, 2008, 31(4): 55-58. (in Chinese)

[22] D Huan, Z H Zhu, H B Geng, et al. TIG wire and arc additive manufacturing of 5A06 aluminum alloy. Journal of Materials Engineering, 2017, 45(3): 66-72. (in Chinese)

[23] D C Lin, G X Wang, T S Srivatsan. A mechanism for the formation of equiaxed grains in welds of aluminum-lithium alloy 2090. Materials Science \& Engineering A (Structural Materials:, Properties, Microstructure and Processing), 2003, 351(1-2): 304-309.

[24] H Wang, W Jiang, J Ouyang, et al. Rapid prototyping of 4043 Al-alloy parts by VP-GTAW. Journal of Materials Processing Technology, 2004, 148(1): 93-102.

[25] B Q Cong, J L Ding, S W Williams. Effect of arc mode in cold metal transfer process on porosity of additively manufactured Al-6.3\%Cu alloy. The International Journal of Advanced Manufacturing Technology, 2015, 76(9-12): 1593-1606.

[26] R Q Wang, Z Q Zheng, Y Y Chen, et al. Effects of Ag, Mg micro-alloying on aging characteristics and microstructure of Al-Cu-Li alloy. Rare Metal Materials and Engineering, 2009, 38(4): 622-626. (in Chinese)

[27] D L Chen, M C Chaturvedi. Effects of welding and weld heat-affected zone simulation on the microstructure and mechanical behavior of a 2195 aluminum-lithium alloy. Metallurgical and Materials Transactions A (Physical Metallurgy and, Materials Science), 2001, 32(11): 2729-2741.

[28] M Murayama, K Hono. Role of Ag and Mg on precipitation of T1 phase in an Al-Cu-Li-Mg-Ag alloy. Scripta Materialia, 2001, 44(4): 701-706.

[29] HY Li, Y Sun, X F Wang, et al. Effect of hot treatment on mechanical properties and microstructure of a new type Al-Cu-Li alloy. Journal of Materials Engineering, 2008, 41(12): 41-45.

\section{Submit your manuscript to a SpringerOpen ${ }^{\circ}$ journal and benefit from:}

- Convenient online submission

- Rigorous peer review

- Open access: articles freely available online

- High visibility within the field

- Retaining the copyright to your article

Submit your next manuscript at springeropen.com 